European Journal of Education (2020) 55 (1): 9-23. $\quad$ DOI: 10.1111/ejed.12381

\title{
Learning for and realising curriculum aspirations through schools as learning organisations
}

\section{Claire Sinnema (1) and Louise Stoll (2)}

(1) Faculty of Education and Social Work, The University of Auckland, Auckland, New Zealand

(2) Department of Learning and Leadership, UCL Institute of Education, London, UK

\section{INTRODUCTION: CURRICULUM FOR THE PRESENT AND THE FUTURE}

As education systems internationally seek to improve outcomes for diverse learners, address excellence and equity simultaneously, strengthen relevance for current and future generations and modernise teaching and learning approaches, attention has increasingly turned to the role of curriculum in such endeavours. This applies to both individual jurisdictions across all continents and to frameworks guiding these efforts, including the kind of curriculum described in the OECD's Education 2030 project (OECD, 2018a). More than ever, the spotlight is on curriculum as a lever for educational improvement and transformation, solving pressing educational problems and meeting urgent societal demands.

In the last decade, curriculum reforms have become increasingly ambitious. Rather than merely revising or adding content and updating requirements, or restructuring traditional elements, reforms often substantially alter the orientation of education, the nature of the aspirations set out and the

\footnotetext{
${ }^{1}$ Claire Sinnema and Louise Stoll contributed equally to this manuscript. Sinnema and Stoll share joint first-authorship.
} 
types of outcomes expected. The case for ensuring that the curriculum is fit for the future is strong and mounting. Looking at average life expectancy figures, in many countries children born today will still be alive in the 22nd century (OECD, 2018a). And with many children born now having "more than 50 percent chance of living to be over 105", it is argued that they will need to be able to reinvent themselves over the years (Gratton \& Scott, 2017, p. 2). For this, ongoing and continuous learning will be essential—indeed, a love of learning. But it is not just about the future. Increasing concerns about child well-being and mental health frequently identify the impact of education accountability system pressures (OECD, 2017), with a growing number of countries including related areas in new curricula. These ambitions create implications for all elements of an education system, including teacher preparation, professional learning, assessment and accountability systems, school and system leadership, and the conditions, context and resources that are conducive to realising such curricula. We use the term "realise" (Sinnema, 2011; Sinnema \& Aitken, 2011) in relation to curriculum because it involves much more than just implementation. As Sinnema noted, the focus when considering the success of curriculum reform efforts is not on adherence to the use of particular strategies in an implementation fidelity sense, but rather to "more generic practices deemed to be indicators of curriculum intentions being realised" (2011, p. 13).

Schools must be open to and ready for significant change to bring new curricula to life in ways that engage students, offer enriching learning experiences and enhance a diverse range of outcomes. "Business as usual" will not suffice. Here, we present a model of curriculum realisation (see Figure 1) that captures challenges associated with enacting curriculum in reform efforts, individual and collective learning which those challenges demand and the role of schools as learning organisations (Kools \& Stoll, 2016 ) — the kinds of schools needed for such an endeavour-in addressing those. 


\section{CHALLENGES ASSOCIATED WITH REALISING NATIONAL CURRICULUM}

\section{ASPIRATIONS}

Realising curriculum aspirations involves at least four key, interrelated challenges. These relate to:

(a) depth of realisation (often more superficial than the deep changes intended by policy makers), (b) the pace of curriculum policy realisation (typically slower than the urgency for change demands), (c) spread of the curriculum (variability across the pockets of the system encountering and responding to curriculum change), and (d) reach of the new curriculum in terms of learners experiencing the aspirations set out in a new or revised curriculum.

\subsection{The depth challenge}

Even when curriculum elements do take hold and become part of practitioners ' educational vocabulary and repertoire, the sheer scope of concepts typically found in curriculum policies often leads to only surface realisation of most. In the curriculum of any one jurisdiction, there can be hundreds of types of aspiration (principles, purposes, values, capabilities, perspectives, crosscurriculum foci, for example). For all elements to be truly realised with depth presents a significant challenge. Consider, for example, a revised curriculum that adds a selection of new curriculum concepts - "digital literacy", “ethical citizenship", "sustainability", "critical thinking”, and so on. Changing the written terms on planning documentation to reflect new elements is straightforward. Beginning to use these terms to describe practices already used is not particularly demanding. Enacting these elements with depth and substance, however, presents a significant challenge. 
Each new curriculum idea or element demands depth of understanding of those with any responsibility for realising curriculum or supporting this. For each element, understanding is required about the: theories underpinning it; rationale for its inclusion; key concepts associated with it; pedagogies most likely to support it; learner progressions in relation to it; and associated assessment practices most helpful to supporting student progress towards each element. Such deep understanding is complex. In the face of such demands, not surprisingly, curriculum change efforts are often characterised by over-assimilation (Sinnema \& Ludlow, 2013) In curriculum terms, over-assimilation is evident when: (a) new elements are mistakenly understood to be similar to or the same as previous curriculum elements (in "this is no different than what we had before" type responses), (b) existing practices are misunderstood to be sufficient for meeting the demands of new curriculum elements (with "I can keep doing what I've always done and don ' $t$ need to do anything different" type responses), and (c) slight revisions to practice are misunderstood to address new curriculum elements that require significant shifts in practice (when people suggest "I can do something just a little bit different, and that will be enough" or similar).

The challenge of ensuring depth of curriculum understanding, and therefore depth in the extent to which curricular reform ideas are realised, is exacerbated by overload both within a curriculum and across the range of education initiatives to which practitioners are expected to respond. This increases the likelihood of surface enactment. The more new curriculum concepts conveyed in a new curriculum, and there are typically many, the greater the load—both workload and cognitive loadon those working with the curriculum (Plass, Morena, \& Brunken, 2010; Sweller, 1994). Where those new curriculum concepts are vital to the success of reform initiatives, energy will have to be directed at ensuring depth in engagement with and understanding of the meanings and significance of new elements, as well as depth in approaches taken to new skill development. 


\subsection{The pace challenge}

In most jurisdictions, the pace of response to curriculum reform rarely matches the level of aspiration for educational change and improvement arising from this reform (Priestley \& Minty, 2013). Often, those leading and designing curriculum reforms cannot resist grand aspirations as they set out new statements of curriculum purpose and vision. By contrast, the pace of change that is evident in even well-intentioned and receptive practitioners' responses is usually much more moderate than what was hoped for (Sinnema, 2011; Sinnema \& Ludlow, 2013). Progress towards new purposes and vision is often less "leaps and bounds" and more tentative "baby steps". This does not suggest that the challenge of pace is one for teachers alone. Pace is impacted directly not only by individual teachers ' receptiveness, understanding, commitment and practice (Mellegård \& Pettersen, 2016) and by teachers ' agency (Priestley, 2015), but also by a complex network of school and system conditions that are more or less conducive to realising curriculum aspirations (Sinnema, 2016).

The pace challenge - the gap between desired and typical (and, arguably, realistic) realisation — is heightened by the political context in which curriculum reform sits. In many jurisdictions, curriculum reforms are tightly connected to Government election cycles (Mills \& McGregor, 2016) and political pressures for curriculum as an improvement lever in a nation's standing in international student achievement assessments. The enthusiasm for aspirations set out in curriculum reform and thirst for change at pace cannot supplant the need to attend to the system's context, capabilities, conditions and resources required for curriculum realisation success. Calls for fast-paced changes that meet system demands in a timely way are seldom realised.

\subsection{The spread challenge}


In any new curriculum effort, there will be variability in teachers ' and schools ' readiness and capabilities to work with the new practices curriculum change requires in ways that bring them to life, with observable differences in practice in line with the new curriculum 's intent. In some cases, curriculum policy revisions are just "catching up" with innovative, forward-thinking curriculum practice and aspirations for learning that some or even many practitioners have already explored or perhaps mastered. Elsewhere, curriculum policy revisions require significant shifts in practice for those whose approach is markedly "behind the curriculum times". Furthermore, some pockets of the system, including those with best intentions, remain untouched by curriculum change. The challenge from a system point of view is how best to ensure that the commitments, understandings and capability required to ensure motivation towards and practices consistent with the new curriculum occur not just in pockets but across the system of focus (Daly, 2010). This demands attention on how to leverage what might be described as "curriculum capital" of those teachers and schools where the curriculum is catching up with them, for the benefit of those teachers and schools that have the challenge and opportunity of "catching up" with the curriculum (Sinnema, Daly, Liou, \& Rodway, 2020). Curriculum capital encompasses the recognition of curriculum realisation challenges and meeting the learning demands to address those challenges (see Figure 1).

\subsection{The reach challenge}

Any valuable curriculum change has at its heart aspirations for children and young people - their experience of schooling and teaching and learning's impact on them. A challenge in curriculum revision processes is to ensure the long chain of influences from a policy document through a system of educational agencies and the spread of professional agency across educators in a range of roles for bringing the curriculum to life in ways that succeed in touching and enhancing students ' experience. 
Addressing the challenge of curriculum reach - and by this we mean reach to students - requires impacts on students and their learning to be the touchstone for determining curriculum realisation success. The reach challenge is illustrated by the persistence of equity and excellence issues, even following national curriculum reforms aimed at addressing those very system issues (OECD, 2010). Future-focused curriculum, in particular, presents ambitious goals for reach impacts and the kinds of learning that would indicate success.

\section{FOUR KEY LEARNING DEMANDS INVOLVED IN MEETING CURRICULUM REALISATION CHALLENGES}

Meeting the challenges of depth, pace, spread and reach demands considerable learning by those charged with enacting curriculum change and those across the system. For national or state/provincial/municipal curriculum aspirations to be realised, learning is essential for each practitioner in every school. Learning also needs to be both collaborative (Andrews-Larson, Wilson, \& Larbi-Cherif, 2017; Liou \& Daly, 2014; Ronfeldt, Farmer, McQueen, \& Grissom, 2015; Tam, 2015; Witterholt, Goedhart, \& Suhre, 2016) and collective, involving knowledge creation around new ways forward (Earl \& Timperley, 2009; Louis, 1994). This learning, from a curriculum point of view, will focus on: committing to the curriculum change; knowing what the curriculum changes are and what they mean; understanding how to respond to the curriculum changes; and improving practice to realise curriculum intentions.

3.1 Committing to the curriculum change

A new curriculum for the future poses challenges that require teachers to think and act differently and to be open to doing this. Receptivity and commitment are prerequisites for responding in practice 
and teaching towards new curriculum aspirations. As many agents of curriculum change as possible must believe in the change, view it as an improvement and commit to playing their part in making it happen. With greater commitment to a new curriculum comes greater likelihood of a successful realisation. This demands that those across a system are willing to learn about the rationale for the change and are open to implications for changing their own practices.

3.2 Knowing what the curriculum changes are and what they mean

To ensure that people's efforts to respond to the curriculum and make changes to their practice are in line with the reform's intentions, deep learning about the nature of new curriculum elements and what they mean for elements remaining from previous curriculum policy are important. From a cognitive point of view, curriculum change agents must know and understand what the changes are, be they "capabilities", “competencies", "progress indicators", "threshold concepts", "levels", “outcome statements' (or other possible new curriculum concepts). They must also understand about the broader curriculum structure and interrelationship between its elements.

3.3 Understanding how to respond to the curriculum changes

Alongside strong knowledge and understandings of what curriculum changes are about, procedural knowledge is required to ensure that curriculum change agents not only know what new curriculum concepts and elements mean, but what this means in terms of response - "what I actually need to do". They need opportunities to learn about new or altered practices they and others should use to realise curriculum aspirations and those to do less of or abandon. Furthermore, they need to learn in ways that strengthen their capabilities for those practices. Developing capability is, therefore, critical 
to realising curriculum aspirations. Explicit opportunities to develop skills associated with curriculum elements known to be important, and practices understood to be necessary, cannot be underestimated. Shifts required in terms of changed, added, revised, and/or abandoned practices bring a demand for learning new capabilities.

\subsection{Improving practice to realise curriculum intentions: Making changes}

Ultimately, curriculum change requires change in practice, not only for teachers, but for everyone with any direct or indirect responsibility for curriculum enactment. For teachers, opportunities are essential to learn in ways that strengthen capabilities required for practices that are consistent with the new curriculum. If a new curriculum promotes children and young people to be adaptive, then the same should apply to those who teach them. To become "knowledge workers" (Schleicher, 2012), confidently collaborating, inquiring into their practice and drawing on other evidence, they will need to have agency around their practice. They will need to become adaptive experts who are able to use deep conceptual knowledge to understand and work effectively to solve problems in novel situations (Le Fevre, Timperley, \& Ell, 2015). They must also break down existing barriers that isolate them from colleagues so that they can support and interrogate each other ' s practice as critical friends, develop ways of making informed choices together and enact and create curriculum.

For school and system leaders, learning is required about what the curriculum changes are and what they require of teachers, as well as practices involved in creating and enhancing school and system conditions that are conducive to this change. Individual teachers can always be found who confidently take on whatever challenges a new curriculum poses, bring it to life, make it their own and engage students in powerful learning experiences. But for systemic and system-wide change, 
whole schools and systems must also engage committedly. Serious system-wide curriculum change is complex and multifaceted; creating lasting change is hard. Reform efforts frequently prepare schools inadequately for the changing environments they encounter (OECD, 2015) and schools are urged to learn fast to deal with associated and growing challenges (Schleicher, 2015).

\subsection{Curriculum capital}

For all the reasons cited, we argue that curriculum realisation requires curriculum capital. As referred to earlier, 'curriculum capital' involves both the recognition of curriculum realisation challenges and meeting the individual and collective learning demands associated with those challenges. As in other forms of capital such as professional capital (Hargreaves \& Fullan, 2012), capital refers to assets that can be leveraged to bring about important goals. The success of curriculum reform demands assets quite particular to curriculum. Our curriculum realisation model proposes four such learning demands relating to commitments, knowledge, understanding and capabilities (see Figure 1) committing to and having a disposition toward curriculum change; knowing what the curriculum changes are and what they mean; understanding how to respond to the curriculum changes; and having the capability to practice in ways that realise curriculum intentions and aspirations (i.e. making changes). These all have a role to play in meeting the challenges of depth, spread, reach and pace.

\section{CREATING CONDITIONS FOR CURRICULUM REALISATION: THE ROLE OF SCHOOLS} AS LEARNING ORGANISATIONS

How might schools be best placed to respond to such challenges and learning demands, to provide their staff with the environment where they can develop adaptive expertise? What conditions in a 
school will "enable teachers to feel agency" (Priestley, 2015)? Elsewhere, one of us has explored a focused and broadened approach to the concept of schools as learning organisations (Kools \& Stoll, 2016; OECD, 2016).

Schools as learning organisations (SLOs) have been viewed as ideal for dealing with a changing external environment and facilitating organisational change and innovation. Relatively little evidence exists of an association with better performance (Caprara, Barbaranelli, Steca, \& Malone, 2006; Schechter \& Qadach, 2012). Encouragingly, positive effects are found with more broadly-defined student outcomes (Silins, Zarins, \& Mulford, 2002). This is important in considering future-focused curricula capabilities, as traditional assessments insufficiently address these. Research on SLOs ' impact also identifies benefits for teachers, including greater individual and collective understanding, improved skills and practices, greater commitment, ability to learn, willingness to work collaboratively and share practice and greater job satisfaction (Erdem, İlğan, \& Uçar, 2014; OECD, 2018b).

Before exploring how the SLO could be marshalled to support realisation of curriculum aspirations, we revisit some conceptual underpinnings. Over three decades of research conceptualising the learning organisation (LO) beyond education identifies characteristics of organisations with the capacity to continuously learn, adapt and change, offering various definitions and approaches, ${ }^{1}$ mostly aligning to one of three perspectives (Yang, Watkins, \& Marsick, 2004) - systems thinking, learning and strategic.

Systems thinking - a LO is an open system, relating to and interacting with the environment. It scans, discovers changes and responds to restore equilibrium. Seeing the bigger picture by looking at the 
system's interrelationships both internally and externally and its adaptive capacity enables it to create alternative futures.

Learning - learning processes of and within the organisation, i.e., organisational learning are fundamental. A LO detects and corrects errors by identifying processes and structures that enable learning. Through social interaction, contextual adjustment and shared cognitive schemes for learning and knowledge creation, it facilitates learning of all its members and continually transforms itself.

Strategic - Learning capacity is created by understanding strategic internal drivers required to develop core learning competencies for the present and future. Exploration and exploitation of new ideas, innovation and inquiry are highlighted. This LO is skilled at creating, acquiring, and transferring knowledge and is able to modify its behaviour to reflect new knowledge and insights.

An integrative perspective (Marsick \& Watkins, 2003; Yang et al., 2004) influenced our thinking. Change and development processes involve a web of connections between people and structure as the organisation engages and supports continuous learning, inquiry and dialogue and team learning, embedding systems for capturing and sharing learning, empowerment, system connection, and strategic leadership.

The concept's applications in education as "school as a learning organisation" (SLO) are also diverse, with proponents sometimes using other terms. Connecting their wider idea to schools, Senge and his colleagues (2012, p.5) view the SLO as one that is "re-created, made vital, and sustainably renewed not by fiat or command, and not by regulation, but by taking a learning orientation. This means involving everyone in the system in expressing their aspirations, building their awareness and 
developing their capabilities together". SLOs are thereby empowered to meet the challenges of educational reforms and improve their performance. For about a decade from the mid-1990s, others also described processes, strategies and structures to enable SLOs to learn and react effectively in uncertain and dynamic environments.

4.1 Dimensions and transversals of schools as learning organisations

The SLO model developed by Kools and Stoll (OECD, 2016) was adapted from Marsick and Watkins ' (school as) learning organisation model (Dimensions of the Learning Organization Questionnaire) (Marsick \& Watkins, 2003), taking account of related, more recent and crossdisciplinary literature and input from an expert network. Here, schools are positioned as learning organisations that "have the capacity to change and adapt routinely to new environments and circumstances as its members, individually and together, learn their way to realising their vision" (p. 63). Seven dimensions are the focus of collective endeavour:

1. Developing and sharing a vision centred on the learning of all students - This vision focuses on enhancing all students' learning experiences and outcomes, both now and for the future. The process involves all staff, students, parents and other stakeholders. It gives everyone a sense of direction, serving as a motivating force for sustained action and aligned practice to achieve individual and school goals.

2. Creating and supporting continuous learning opportunities for all staff - All staff are engaged in career-long, personally relevant, high-quality continuous professional learning. This focuses on student learning and school goals, blending workplace and external learning opportunities and incorporating challenge, reflection, analysis and practice. The culture and structures support this. 
3. Promoting team learning and collaboration among staff - Colleagues learn how to think and act together, sharing their collective learning as they network. Trust and mutual respect provide a foundation for cooperation. Time is created for related activity, to reflect together on solving problems and for focused conversations about enhancing student learning and staff practice.

4. Establishing a culture of inquiry, innovation and exploration - A spirit of inquiry, initiative and willingness to experiment with new ideas and practices are pervasive. Staff are able and willing to avoid snap judgements, consider alternative perspectives, pose increasingly focused questions, and investigate and learn from problems of practice. This leads to more informed decisions, greater confidence and adaptability.

5. Embedding systems for collecting and exchanging knowledge and learning - Processes, strategies and structures enable them to learn and react quickly in uncertain and changing environments. They systematically collect, analyse and exchange knowledge, revise their theories, plans and strategies in light of new evidence and processing through regular dialogue.

6. Learning with and from the external environment and larger learning system - Highly sensitive to their external environment, they proactively and continuously scan it. They monitor and respond to external challenges and opportunities and form a wide range of networks and partnerships to develop and maintain the necessary capital.

7. Modelling and growing learning leadership - Learning leadership binds the SLO together. It provides direction for learning, ensuring that actions are consistent with vision, goals and values. School leaders establish a learning culture, promote and facilitate organisational learning and develop other leaders. Modelling and championing deep professionalism within and beyond their schools, they engage in professional learning and create a safe, trusting and creative culture and facilitative structures. 
Each dimension is composed of a set of elements, including action processes to enhance the dimension and learning culture outcomes - what it looks like, sounds like, feels like, etc. Together, the action-oriented dimensions are intended to add up to a sustainable learning culture, with the whole being greater than the sum of the parts. Cross-cutting transversal themes, $4 \mathrm{~T}$ 's - trust, time, technology and thinking together - flow through the dimensions, exerting influence across the whole.

Many schools in different countries are still far removed from the ideal of being a learning organisation, although external pressures to make this transformation are mounting; major curriculum change being just one example. Exploring new ways of doing things and striving for lasting innovations in educational practice to realise curriculum change are now fundamental.

\section{ADDRESSING CURRICULUM REALISATION CHALLENGES: THE ROLE OF SCHOOLS}

\section{AS LEARNING ORGANISATIONS DIMENSIONS AND TRANSVERSALS}

In the following section, we highlight how each of the four curriculum challenges associated with realising a future-focused curriculum can be addressed by the dimensions and transversals of schools as a learning organisation. ${ }^{2}$

\subsection{Dimensions}

The dimensions have a particular role to play in efforts to bring national curricula to life. For each realisation challenge (depth, pace, spread and reach) we touch on some SLO dimensions that will 
support the collaborative and collective learning demands relating to commitment, knowledge, understanding and capability. ${ }^{3}$

\subsubsection{Addressing the depth challenge}

Developing and sharing a vision centred on the learning of all students play an important role in tackling this challenge. The vision needs to convey depth and commitment to that vision's depth must be shared to ensure aligned action. A curriculum that takes seriously, for example, changing positioning of students in their learning so that they have genuine agency requires that that vision be shared by students themselves, parents, community, partners and educators. Furthermore, given the potential for student agency to be misunderstood (perhaps as giving students choice, rather than full agency), all those who share the vision need opportunities to understand and make sense of what may seem complex and confusing curriculum policy (Priestley, Minty, \& Eager, 2014) in order to create and share a full and deep version of the vision.

Combatting the over-assimilation of new curriculum ideas that are central to this challenge requires creating and supporting continuous learning opportunities for all staff. Learning opportunities should be underpinned by deep knowledge about powerful professional learning (Timperley, Wilson, Barrar, \& Fung, 2007). Through these, educators can both learn what new and multiple curriculum elements require (alone and in combination) - deep knowledge and powerful practice - and unlearn current practices which are barriers. Teaching can become highly ritualised, as patterns of practice become embedded. This may be good when those practices are in line with curriculum aspirations, but in the context of new curricula and the need for adaptive expertise some will inevitably need change. This makes professional learning that challenges thinking vital. 
Teachers ' efforts to give life to curricula that emphasise future-oriented competencies that actively involve students in transforming societies by creating new value, reconciling tensions and dilemmas and taking responsibility are likely to involve a degree of risk. If they do not, they are unlikely to push towards the depth of the curriculum element intended by the policy. Unlike curricula that emphasise the delivery of content and students ' recall and passive displays of understanding, what new curricula demand of students presents professional risks for teachers who are unfamiliar with such demands. Schools that establish a culture of inquiry, innovation and exploration provide teachers with the supportive conditions and culture that encourage greater open-mindedness, allow them to try new things and take risks, learn from mistakes and inquire in ways that enable colleagues to learn from others ' inquiry into innovations.

The knowledge, expertise, wisdom and resources required to bring a new curriculum fully to life in ways that represent the curriculum's depth are almost certainly not held in full by every leader and practitioner involved in enacting it. This makes it essential that schools promote team learning and collaboration among staff. In a curriculum change context, new and experienced practitioners must work towards new or altered curriculum goals or priorities, try associated new practices and revise or abandon at least some previous curriculum priorities and approaches. Strong relational ties are essential for educators to support one another effectively and professionally through those curriculum changes. Problems are more likely to be shared and colleagues can learn from others as they reflect together on their experiences.

\subsubsection{Addressing the pace challenge}

Curriculum realisation is unlikely to be smooth - most likely it will involve issues and problems, not all anticipated. Schools will be better placed to solve these when they are already creating and 
supporting continuous learning opportunities for all staff. Embedded professional learning supports staff as curricula then become a focus of well-planned learning processes. The notion of "continuous" professional learning is important, since new curricula and what they require cannot be learnt through one-off or short-term professional learning approaches. In addition, professional learning geared to meet individual teachers ' curriculum learning needs is differentiated to ensure that those who are ready to move faster are not held back, whilst those who are more reticent or need greater support have extra time. In this way, the overall challenge of appropriate pace can be met.

When schools embed systems and routines for collecting and exchanging knowledge and learning about a new curriculum, they can maximise the pace at which its aspirations and their own aspirations for it are realised. Simple routines can be established that ensure that the curriculum is the focus of conversations, including, for example, staff meeting agendas that consistently schedule " 10 min curriculum conversations", norms of data team meetings that require the relationship to new elements of the curriculum to be considered and systems for ensuring that developing expertise that is consistent with the new curriculum is shared rather than leaving this to chance.

Increasing the pace of curriculum change can also be supported with efforts to promote less of an individual classroom or school orientation and more of a system orientation, inherent in learning with and from the external environment and larger learning system. Being more receptive to ideas coming from outside suggests that teachers and leaders will be more open to implications of societal and international concerns such as student well-being and the need for critical and creative thinkers. Inquiry-oriented standards for teaching proposed by Sinnema, Meyer, and Aitken (2017) also highlight how teachers must inquire in ways that critique how the structures and policies of the wider education context impact on their work. Greater understanding of system-level issues and the associated rationale for curriculum change should lead to a greater shared sense of urgency for 
change and commitment to taking action that supports the collective vision as expressed in a national curriculum. Involving external partners who bring different expertise can also expediate specific activity, for example partners in research and curriculum organisations and networks who can help to design assessments of student capabilities.

In SLOs, leaders are forward-thinking, with fingers on the pulse of changes in the world around them. They understand the importance of preparing students for a world that is different from that in which they grew up and explore how a new curriculum can help their school with this challenging endeavour. Recognising urgency for change, they make carefully considered decisions about what to abandon to make room for new practices, whilst working to create a culture and structures where commitment, energy and agency for curriculum change will be embraced and thrive. Through modelling and growing learning leadership throughout their schools and in partnership with others, they widen the pool of influence. This helps to pick up the pace as teachers, students and community leaders are supported in becoming catalysts for curriculum change.

\subsubsection{Addressing the spread challenge}

Creating and supporting continuous learning opportunities for all staff means just that. A new curriculum requires new learning for everyone. Just as students ' learning has to be adapted to meet individual needs, professional learning experiences have to address the needs of diverse staff. People will not all struggle with the same aspects of a new curriculum. Relevant professional learning will reach many more staff if it attends to their specific context, students and curriculum challenges. Support staff must also be included, as they are essential players in professional learning communities (Bolam, Stoll, \& Greenwood, 2007). 
Addressing spread across a school can be enhanced by promoting team learning and collaboration among all staff. Staff with "curriculum capital" have greater opportunities to communicate curriculum change messages and spread curriculum knowledge, experience and expertise when there is strong collaboration among staff, strong networks and robust structures and routines that support these. Strong social networks that are supportive of curriculum change are fundamental to spreading understandings and practices that are reflective of any new curriculum (Liou, Daly, Brown, \& del Fresno, 2015; Siciliano, Moolenaar, Daly, \& Liou, 2017; Sinnema et al., 2020). Relevant activities include co-design and planning of contextualised curriculum experiences, team teaching, supportive peer observations and feedback and chances to practise and refine strategies together in a safe environment. Team learning through collaborative design that is explicitly linked to the curriculum impacts the implementation of curriculum change (Voogt, Pieters, \& Handelzalts, 2016).

Because learning with and from the external environment and larger learning system is fundamental to SLOs, spread is more likely. Individuals and groups connect with colleagues in external social networks, other schools and organisations, giving them access to a wider set of knowledge, understandings and practices around the future-focused curriculum and opportunities to connect across boundaries facilitating system-wide spread. As external partners include those from other disciplines, for example social work, health, the arts, business, etc, more diverse perspectives can be brought into play, enabling schools to tackle student learning problems from many more angles.

The more individuals stepping up as proactive curriculum change agents, not only amending and developing their own knowledge and practice, but influencing and supporting peers to do so, the greater the chance that new curricula will take hold and flourish and that aspirations will be realised. So, modelling and growing learning leadership are fundamental resources for spread. Principals and senior leaders are vitally important in bringing the school community and partners together, helping 
everyone to learn about the curriculum's rationale and leading development of a meaningful and shared school-based vision of the curriculum that will inspire its realisation in all its guises. They ensure aligned activities and behaviours. Also, they identify and develop others throughout the school - including students - who see themselves as influential learning leaders and are willing to take responsibility for different pieces of the puzzle, thereby sharing the load and helping to develop critical mass and sustainable curriculum change.

\subsubsection{Addressing the reach challenge}

SLOs are fundamentally concerned with emerging and future trends, as well as ensuring quality and equity. This is highlighted when developing and sharing a vision centred on the learning of all students. Indeed, from our perspective, schools should not be called learning organisations if they are not thinking about preparing their students for a changing future. This means that engaging with, codesigning and bringing to life future-focused curricula should be meaningful and energising for SLOs, albeit a serious undertaking. Ensuring that the curriculum reaches learners-impacting day-today and long-term experiences of curriculum, teaching and learning, and the capabilities it promotes-means that it has to matter to them. So their involvement in vision development processes is vital; they do not just experience others ' curriculum vision - they are essential contributors, both to national curricula and more local/school-based curricula.

For a new curriculum to reach all students in ways that alter and improve the outcomes and achievements they experience, continuous professional learning opportunities for all staff need to "start with the end in mind" - decisions about what adults have to learn are based on problems they encounter with their teaching, including when the intended curriculum does not "reach" students. As a new curriculum is brought to life, an SLO ' s professional learning is oriented towards ensuring 
high quality student learning experiences and well-being, learner progression and designing ways of assessing that students ' needs have been met and that their learning has been enhanced.

A touchstone for reach of a new curriculum is when students are deeply engaged in bringing it to life. In SLOs establishing a culture of inquiry, innovation and exploration means just that; students are key players in curriculum realisation. Their skills are developed and opportunities are created for them to explore aspects of curriculum elements through inquiry-based learning approaches. Everyone is responsible for finding ways to get the most out of the new curriculum, staff are comfortable with students taking an active, self-regulating role in their learning, and confident to facilitate this - or try to do so, knowing that problems and mistakes are seen by everyone as further opportunities for learning.

SLOs are well-placed to draw on a variety of approaches to establishing embedded systems for collecting and exchanging knowledge and learning about the impact of their work. To address the challenge reach, the impacts of focus must explicitly include those relating to students - their learning and well-being. This demands that educators scrutinise new curricula to determine how they can best access or design systems that will provide process, progress and outcome data and other evidence they need to ensure that the new curriculum is having a positive impact. SLOs create systems for examining progress towards and gaps between current and expected impact and provide opportunities for dialogue, using interpretation of new curriculum elements as the touchstone for examining progress. Connecting to depth, attention is then paid to what could indicate surfacelevel progress versus progress reflecting the depth of new curriculum elements. Engagement with external research evidence also supports SLOs in designing school-based curriculum that are more likely to enhance students ' experiences and capabilities. 
Schools do not always have immediate access to all the staff or resources needed to fully realise curriculum aspirations. With openness to learning with and from the external environment and larger learning system (the local community, a wide range of partnerships and external networks) comes greater assurance of curriculum reaching students. External partnerships, collaborations and exchanges are certain to support schools and give effect to elements of a new curriculum. There are numerous possibilities, be it curriculum aspirations for new learning areas (e.g., languages), for new competencies (e.g., digital competencies) or for new curriculum constructs (e.g., mindfulness, growth-mindset, problem-solving, or global-mindedness). When schools are open systems, they can quickly respond to opportunities to learn from people and organisations, including other schools and wider agencies, in ways that enable them to ensure that their knowledge and resources for realising curriculum goals are likely to reach all students.

\subsection{Transversals}

In cutting across the seven dimensions, the transversals (time, technology, trust and thinking together) tap into and can influence each of the curriculum demands.

Time is vital for the endeavour of realising curriculum aspirations. SLOs know that this cannot be a quick fix: any serious learning takes time (Stoll, Fink, \& Earl, 2003). Immediate and fast-paced enactment may give the illusion of curriculum reform success, but this may mask less commitment than if more time is spent together generating the shared understandings and aspirations necessary for longer-term success. Necessary time is given to address depth of vision, professional learning, collaboration and knowledge exchange, spread within the school, across its networks and with other external partners, for ultimate reach, which takes longer. All the while, pressures for speed and 
understanding that students ' time in school is precious and limited are balanced with variations in pace that attend to differential needs and situations.

Technology is marshalled creatively. For spread and depth it is oriented towards enhancing knowledge exchange, social networking and productive collaboration and ensuring blended and wider access to professional learning and leadership development. For reach, it can support pedagogy for enacting curricula, support management and circulation of the variety of data collected to assess capabilities and evaluate theories of change and aspects of progress toward curriculum realisation.

Trust is at the heart of deep relationships that underpin productive activity in schools (Bryk \& Schneider, 2003) and system improvement (Fink, 2016). It is essential to depth, spread and reach. Risk taking associated with experimentation and opening up practice to the scrutiny and challenge of others depends on trust. Through meaningful, supported collaborative activity on local vision development, and design, planning, enacting and assessing curriculum in schools, trust also builds and pace picks up as students take increasing responsibility for their own learning.

Thinking together is part of the lifeblood of schools as learning organisations. It is what gives them their strength and vitality, enabling them to establish and maintain a rhythm of learning, change and innovation (Kools \& Stoll, 2016; OECD, 2016). This rhythm affords a pace whereby curriculum change, like any other change, can be integrated into its deep and widely spread inquiry cycle of learning, unlearning and relearning its way into the future. And reach is consistently at the core of collective learning, knowledge generation and activity around a new curriculum-everyone knows and believes that it has to make a difference to students ' learning experiences and capabilities. 


\section{CONCLUSION}

The approach to realising a new curriculum with all its complexities, particularly a curriculum that affords practitioners high levels of flexibility and autonomy, will necessarily be different across schools, given variations in context and capacity. There are considerable challenges (depth, spread, reach and pace) and associated learning demands (commitment, knowledge, understanding and capability) in ensuring that the curriculum is brought to life in ways that are meaningful, engaging and enriching for all. Addressing those challenges and meeting those demands are vital if curriculum is to contribute to equity and excellence for all students across the system. Schools must develop the capacity for learning and curriculum capital that will enable them to get and make the most out of a future-focused curriculum. It may well demand significant alteration of beliefs, assumptions, knowledge, understanding and practice for many of those expected to be agents of curriculum change. Schools that are learning organisations, we would argue, provide the ideal conditions for developing and moving around curriculum capital. Their staff deeply understand and take seriously the challenges and learning demands associated with realising a new curriculum. Their stimulating, supportive and collaborative learning - individual, collaborative and collective - environments make it more likely that individuals and groups will believe that the effort is worthwhile and that they have much to offer in elevating and enhancing curriculum experiences in their schools and across a system. Of course, their task is more feasible in systems that are also learning, and provide the necessary conditions to support the realisation of curriculum aspirations.

\section{REFERENCES}

Andrews-Larson, C., Wilson, J. \& Larbi-Cherif, A. (2017). Instructional improvement and teachers' collaborative conversations: The role of focus and facilitation. Teachers College Record, 119, 1-37. 
Bolam, R., Stoll, L., \& Greenwood, A. (2007). The involvement of support staff in professional leaning communities. In L. Stoll \& K. Seashore Louis (Eds.), Professional learning communities: Divergence, depth and dilemmas (pp. 17-29). Maidenhead, UK: Open University Press.

Bryk, A. S., \& Schneider, B. L. (2003). Trust in schools: A core resource for school reform. Educational Leadership, 60, 40-45.

Caprara, G. V., Barbaranelli, C., Steca, P., \& Malone, P. S. (2006). Teachers' self-efficacy beliefs as determinants of job satisfaction and students' academic achievement: A study at the school level. Journal of School Psychology, 44, 473-490. https://doi.org/10.1016/j.jsp.2006.09.001

Daly, A. J. (2010). Social network theory and educational change. Cambridge, MA: Harvard Education Press.

Earl, L., \& Timperley, H. (Eds.) (2009). Professional learning conversations: Challenges in using evidence for improvement. Dordrecht, the Netherlands: Springer.

Education Wales. (2017). Education in Wales: Our national mission, Action Plan 2017-21 . Retrieved from https ://gov.wales/sites/default/files/publications/2018-03/education-in-wales-ournational-mission.pdf

Erdem, M., İlğan, A., \& Uçar, H. (2014). Relationship between learning organization and job satisfaction of primary school teachers. International Online Journal of Educational Sciences, 6, 820. https://doi.org/10.15345/iojes.2014.01.002 
Fink, D. (Ed.) (2016). Trust and verify: The real keys to school improvement. London, UK: UCL IOE Press.

Gratton, L. \& Scott, A. (2017). The 100-year life: Living and working in an age of longevity. London, UK: Bloomsbury Business.

Hargreaves, A., \& Fullan, M. (2012). Professional capital: Transforming teaching in every school. New York, NY: Teachers College Press.

Kools, M., \& Stoll, L. (2016). What makes a school a learning organisation? In OECD education working papers (Vol. 2016). Paris, France: OECD Publishing.

Le Fevre, D., Timperley, H. S. \& Ell, F. (2015). Curriculum and pedagogy: The future of teacher professional learning and the development of adaptive expertise. In D. Wyse, L. Hayward, \& J. Pandya (Eds.), The SAGE handbook of curriculum, pedagogy and assessment (Vol. 2 , pp. 309-324). London: SAGE.

Liou, Y.-H., \& Daly, A. J. (2014). Closer to learning: Social networks, trust, and professional communities. Journal of School Leadership, 24, 753 -795. https://doi.org/10.1177/1052684614 02400407

Liou, Y.-H., Daly, A. J., Brown, C., \& del Fresno, M. (2015). Foregrounding the role of relationships in reform. The International Journal of Educational Management, 29, 819-837. https://doi.org/10.1108/IJEM-05-2015-0063 
Louis, K. S. (1994). Beyond "managed change": Rethinking how schools improve. School Effectiveness and School Improvement, 5, 2-24.

Marsick, V. J. , \& Watkins, K. E. (2003). Demonstrating the value of an organization's learning culture: The dimensions of the learning organization questionnaire. Advances in Developing Human Resources, 5, 132-151.

Mellegård , I., \& Pettersen, K. D. (2016). Teachers' response to curriculum change: Balancing external and internal change forces. Teacher Development, 20, 181-196. https://doi.org/10.1080/13664 530.2016.1143871

Mills, M., \& McGregor, G. (2016). Learning not borrowing from the Queensland education system: Lessons on curricular, pedagogical and assessment reform. Curriculum Journal, 27, 113-133. https://doi.org/10.1080/09585176.2016.1147969

O'Donnell, C. L. (2008). Defining, conceptualizing, and measuring fidelity of implementation and its relationship to outcomes in K-12 curriculum intervention research. Review of Educational Research, 78, 33-84. https ://doi.org/10.3102/00346 54307313793

OECD (2010). PISA 2009 results: Overcoming social background-Equity in learning opportunities and outcomes (Vol. II). Paris: OECD. https ://www.oecd.org/pisa/pisaproducts/48852 584.pdf

OECD (2015). Schooling redesigned: Towards innovative learning systems, educational research and innovation. Paris: OECD. Retrieved from https ://www.oecd.org/education/schoolingredesigned-9789264245914-en.htm 
OECD (2016). What makes a school a learning organisation: A guide for policymakers, school leaders and teachers. Paris: OECD. Retrieved from https://www.oecd.org/education/school/schoollearning-organisation.pdf

OECD (2017). PISA 2015 results (Volume III): Students' well-being, PISA. Paris: OECD. Retrieved from https://www.oecd.org/education/pisa-2015-results-volume-iii-9789264273856-en.htm

OECD (2018a). The future of education and skills: Education 2030. Paris: OECD. Retrieved from https://www.oecd.org/education/2030/E2030\%20Position\%20Paper\%20(05.04.2018).pdf

OECD (2018b). Developing schools into learning organisations - Wales. Paris: OECD. Retrieved from https://www.oecd.org/education/developing-schools-as-learning-organisations-in-wales-97892 64307193-en.htm

Plass, J. L., Morena, R., \& Brunken, R. (Eds.). (2010). Cognitive load theory. Cambridge, UK: Cambridge University Press.

Priestley, M. (2015). Teacher agency: An ecological approach (1st ed.). London, UK: Bloomsbury Publishing.

Priestley, M., \& Minty, S. (2013). Curriculum for excellence: ‘A brilliant idea, but...'. Scottish Educational Review, 45, 39-52. 
Priestley, M., Minty, S., \& Eager, M. ( 2014 ). School-based curriculum development in Scotland: Curriculum policy and enactment. Pedagogy, Culture and Society, 22, 189-211. https://doi.org/10.1080/14681 366.2013.812137

Ronfeldt, M., Farmer, S. O., McQueen, K., \& Grissom, J. A. (2015). Teacher collaboration in instructional teams and student achievement. American Educational Research Journal, 52, 475-514. https://doi.org/10.3102/0002831215 585562

Schechter, C. , \& Qadach, M. (2012). Toward an organizational model of change in elementary schools: The contribution of organizational learning mechanisms. Educational Administration Quarterly, 48, 116-153 . https ://doi.org/10.1177/00131 61X11419653

Schleicher, A. (2012). Preparing teachers and developing school leaders for the 21 st century: Lessons from around the world. Paris, France: OECD.

Schleicher, A. (2015). Schools for 21st-century learners: Strong leaders, confident teachers, innovative approaches, international summit on the teaching profession. Paris, France: OECD.

Senge, P. M., Cambron-McCabe, N., Lucas, T., Smith, B., \& Dutton, J. (2012). Schools that learn: A fifth discipline fieldbook for educators, parents, and everyone who cares about education (2nd ed.). London, UK: Nicholas Brealey.

Siciliano, M. D., Moolenaar, N. M., Daly, A. J., \& Liou, Y. H. (2017). A cognitive perspective on policy implementation: Reform beliefs, sensemaking, and social networks. Public Administration Review, 77, 889-901. https://doi.org/10.1111/puar.12797 
Silins, H., Zarins, S., \& Mulford , B. (2002). What characteristics and processes define a school as a learning organisation? Is it a useful concept to apply to schools? International Education Journal, 3, 24-32.

Sinnema, C. (2011). Monitoring and evaluating curriculum implementation. Final evaluation report on the implementation of the New Zealand curriculum 2008-2009. Wellington, New Zealand: The New Zealand Ministry of Education.

Sinnema, C. (2016). The ebb and flow of curricular autonomy: Balance between local freedom and national prescription in curricula . In D. Wyse, L. Hayward, \& J. Z. Pandya (Eds.), The SAGE handbook of curriculum, pedagogy and assessment (pp. 965-983 ). London: SAGE Publications Ltd.

Sinnema, C. , \& Aitken , G. (2011). Teaching as inquiry in the New Zealand curriculum: Origins and implementation. In J. Parr, H. Hedges, \& S. May (Eds.), Changing trajectories of teaching and learning. Wellington, New Zealand: NZCER.

Sinnema, C., Aitken, G., \& Meyer, F. (2017). Capturing the complex, context-bound and active nature of teaching through inquiry-oriented standards for teaching. Journal of Teacher Education, 68, 9-27. https://doi.org/10.1177/00224 87116668017

Sinnema, C., Daly, A. J., Liou, Y.-H., \& Rodway, J. (2020). Exploring the communities of learning policy in New Zealand using social network analysis: A case study of leadership, expertise, and networks. International Journal of Education Research, 99, 101492.https://doi.org/10.1016/j.ijer.2019.10.002 
Sinnema, C., \& Ludlow, L. H. (2013). A Rasch approach to the measurement of responsive curriculum practice in the context of curricula reform. The International Journal of Educational and Psychological Assessment, 12, 33-57. http://tijepa.webs.com/Vol\%2012.2/A3_12.2.pdf

Stoll, L., Fink, D., \& Earl, L. (2003). It's about learning (and it's about time): What's in it for schools? London, UK: RoutledgeFalmer.

Sweller, J. (1994). Cognitive load theory, learning difficulty and instructional design. Learning and Instruction, 4, 295-312. https ://doi.org/10.1016/0959-4752(94)90003-5

Tam, A. C. F. (2015). The role of a professional learning community in teacher change: A perspective from beliefs and practices. Teachers and Teaching: Theory and Practice, 21, 22-43. https ://doi.org/10.1080/13540 602.2014.928122

Timperley, H., Wilson, A., Barrar, H., \& Fung, I. (2007). Teacher professional learning and development: Best evidence synthesis iteration. Wellington, New Zealand: Ministry of Education. Retrieved from www.oecd.org/education/preschoolandschool/48727127.pdf

Voogt, J. M., Pieters, J. M., \& Handelzalts, A. (2016). Teacher collaboration in curriculum design teams: Effects, mechanisms, and conditions. Educational Research and Evaluation, 22 121-140. https://doi.org/10.1080/13803611.2016.1247725 
Witterholt, M., Goedhart, M., \& Suhre, C. (2016). The impact of peer collaboration on teachers' practical knowledge. European Journal of Teacher Education, 39 (1), 126-143.

https://doi.org/10.1080/02619 768.2015.1109624

Yang, B., Watkins, K. E., \& Marsick V. J. (2004). The construct of the learning organization:

Dimensions, measurement, and validation. Human Resource Development Quarterly, 15 (1), 31-55. https://doi.org/10.1002/hrdq.1086 
Figure 1. Model of curriculum realisation through schools as learning organisations

\section{CURRICULUM REALISATION}

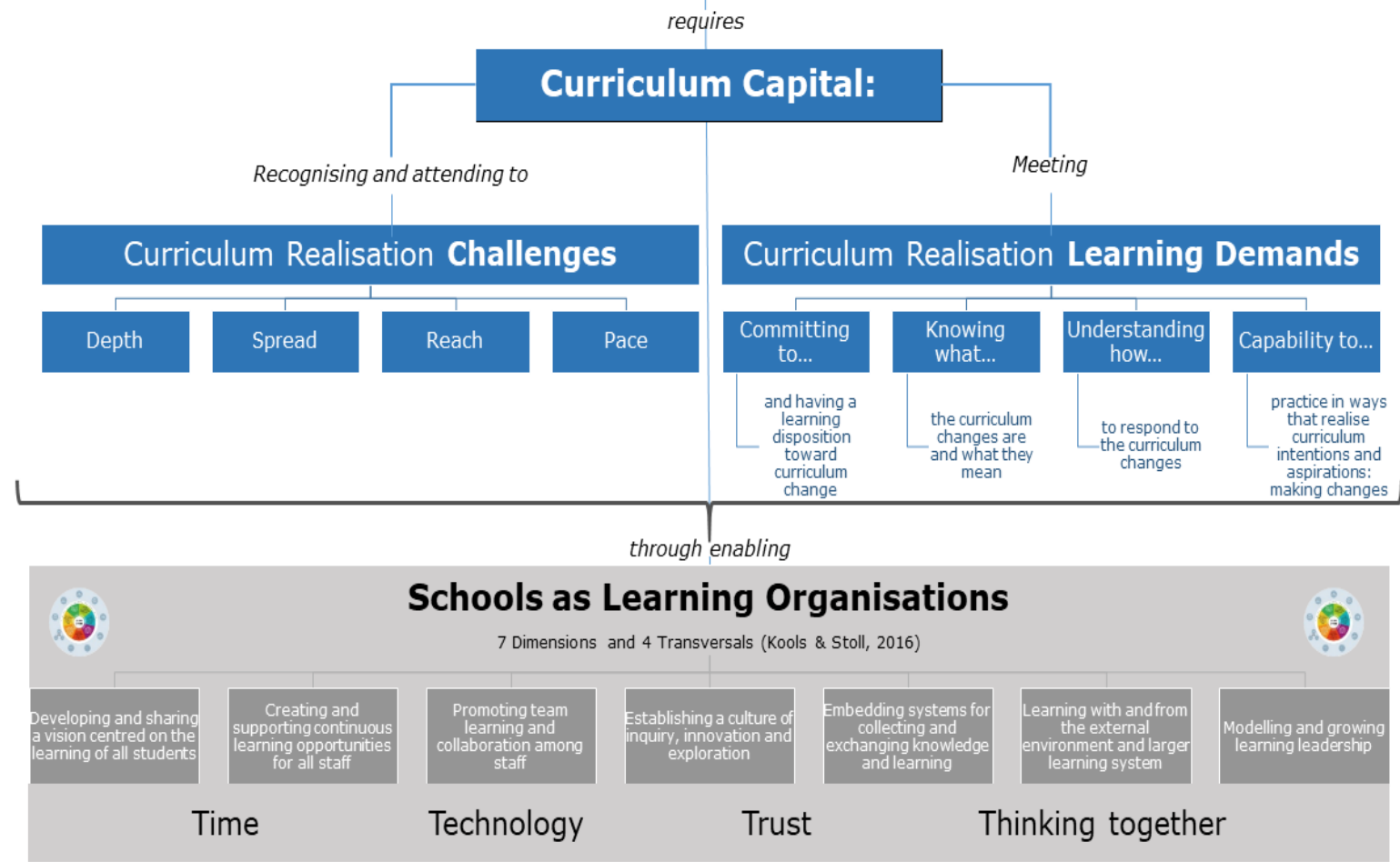


${ }^{1}$ For detailed references, see Kools and Stoll (2016).

${ }^{2}$ Stoll has been observing and was involved in early efforts to support its application in Wales, the first country to apply the SLO findings in an ongoing national endeavour to support curriculum realisation (Education Wales, 2017; OECD, 2018b). Sinnema has also been involved in the curriculum reform work in Wales as a contributor of think pieces for the curriculum development process, a member of the Welsh Government Curriculum and Assessment Group, and an external expert member of the OECD review team assessing curriculum reform progress.

${ }^{3}$ Other dimensions, inevitably, come into play in each of these challenges, but are not discussed here given article word limitations. We have, however, addressed continuous professional learning across all four challenges. 